\title{
Mechanisms of PEDF-mediated protection against reactive oxygen species damage in diabetic retinopathy and neuropathy
}

\author{
Mina Elahy, Swati Baindur-Hudson, Vinicius F Cruzat ${ }^{1,2}$, Philip Newsholme ${ }^{1,2}$ and \\ Crispin R Dass ${ }^{2,3}$ \\ College of Health and Biomedicine, Victoria University, St Albans, Victoria 3021, Australia \\ ${ }^{1}$ School of Biomedical Sciences, ${ }^{2}$ Biosciences Research Precinct, and ${ }^{3}$ School of Pharmacy, Curtin University, \\ Bentley, Perth, Western Australia 6102, Australia
}

Correspondence should be addressed to $C$ R Dass

Email

Crispin.Dass@curtin.edu.au

\begin{abstract}
Pigment epithelium-derived factor (PEDF) is a pluripotent glycoprotein belonging to the serpin family. PEDF can stimulate several physiological processes such as angiogenesis, cell proliferation, and survival. Oxidative stress plays an important role in the occurrence of diabetic retinopathy (DR), which is the major cause of blindness in young diabetic adults. PEDF plays a protective role in DR and there is accumulating evidence of the neuroprotective effect of PEDF. In this paper, we review the role of PEDF and the mechanisms involved in its antioxidative, anti-inflammatory, and neuroprotective properties.
\end{abstract}

\author{
Key Words \\ - PEDF \\ - diabetes \\ - oxidative stress \\ - pericyte \\ signal transduction \\ - redox balance
}

Journal of Endocrinology (2014) 222, R129-R139

\section{Introduction}

Nontransmissible chronic diseases are increasing all over the world, resulting in financial and logistical challenges for all health care systems in the 21st century. Contributing to this scenario, diabetic retinopathy (DR), one of the most devastating acquired vascular complications of diabetes mellitus, is responsible for affecting overall life quality worldwide. It has been estimated that the number of Americans suffering from DR will be 16 million by 2050 (Milne \& Brownstein 2013).

In DR disease, premature death of pericytes occurs via apoptosis, and may result in a dramatic reduction in retinal function, due to the formation of pericyte ghosts in the basement membrane, subsequently leading to nonproliferative DR (Amano et al. 2005, Hammes 2005, Ejaz 2008). Pericytes are one of the main cell types of retinal microvessels, playing an important role in retinal capillary homeostasis via control of proliferation of endothelial cells (ECs). Furthermore, experimental evidence shows that pericytes are responsible for protection of ECs against lipid peroxide-induced injuries, preserving their capacity to produce prostacyclins (Yamagishi et al. $1993 a, b)$. Therefore, in DR, major structural change occurs, including thickening of the basement membrane, hyperpermeability, and the formation of microaneurysms. These changes ultimately predispose the capillaries to neovascularization, angiogenesis, ECs injuries, and the proliferative form of DR, which mostly results in vision loss due to macular edema (Yamagishi \& Matsui 2011).

Metabolic and signaling disturbances in diabetes can initiate apoptosis in retinal capillaries and may culminate

Published by Bioscientifica Ltd. 
in pericyte apoptosis and depletion (Ejaz 2008, Yamagishi $\&$ Matsui 2011). These disturbances include formation of advanced glycation end products (AGEs), upregulation of protein kinase $\mathrm{C}$, the polyol pathway, focal leukostasis, and oxidative stress. In DR, promoted by an islet-based inability to secrete or failure of target tissues to optimally respond to insulin, hyperglycemic events are common and these, per se, promote the aberrant production of reactive oxygen species (ROS) and an overwhelmed detoxification system in insulin-responsive cells, which leads to oxidative stress (Yamagishi et al. 2002a, Newsholme et al. 2012). In this context, pigment epithelium-derived factor (PEDF, a glycoprotein (50 kDa, 418 amino acids) widely expressed in most body tissues) exerts anti-inflammatory functions, attenuating the expression of chemical mediators, such as vascular endothelial growth factor (VEGF), tumor necrosis factor alpha $(\mathrm{TNF} \alpha)$, and intercellular adhesion molecule 1 (ICAM1) in retinal vascular ECs (Zhang et al. 2008, 2011).

Recent advances in molecular and cell biology have provided the basis for the discovery of inhibitory activity of PEDF against cancers, such as osteosarcoma (Dass et al. 2007, Ek et al. 2007a,b,c, Ta et al. 2009), breast and prostate cancers (Filiz \& Dass 2012), and chondrosarcoma (Tan et al. 2010). It also protects against oxidative stress, which includes diabetic damage in the eye and angiogenicrelated disease (Yamagishi et al. 2003), vascular injuries (Yoshida et al. 2006, Nakamura et al. 2007), and neurotoxicity (Araki et al. 1998, Yabe et al. 2005a). However, recent work has provided evidence that in uncontrolled diabetes, PEDF levels in the retina and vitreous fluids are low, which may contribute to proliferative DR (Boehm et al. 2003, Yokoi et al. 2007). Considering the epidemic challenge of diabetes and its complications, a better understanding of DR, its mechanisms, and targets will be essential to future new strategies and treatments. In the following sections, first the mechanisms and pathways that are involved in the development of DR and pericyte loss is discussed and next the inhibitory and protective role of PEDF will be presented.

\section{Role of oxidative stress and inflammation in the development of DR}

The Maillard process, a nonenzymatic reaction between a reducing sugar and free amino groups in proteins (the carbonyl group of the sugar reacts with the amino group producing $N$-substituted glycosylamine and water), is important for the development of DR. The glycosylamine undergoes Amadori rearrangement to form various ketosamines that undergo further rearrangement, important for the creation of glycation products which can undergo further complex reactions such as dehydration, condensation, and rearrangement, and become permanently cross-linked to form AGEs (Sato et al. 2006, Yamagishi et al. 2007a, Yamagishi \& Matsui 2011). During the progression of diabetes, the formation and accumulation of AGEs increase. Retinal pericytes are associated with higher levels of AGEs, which then contribute to retinal vascular hyperpermeability and DR (Yamagishi et al. 2002a, 2007a, Sato et al. 2006). AGEs, and signaling stimulated by their receptors (RAGEs), can induce the generation of intracellular ROS and provoke oxidative stress, initiating vascular inflammation and complications in diabetes (Fukami et al. 2004). Furthermore, AGE-RAGE interaction can also cause apoptosis in retinal pericytes and become embroiled in the early phase of DR (Hammes et al. 1999, Yamagishi et al. 2002a,b).

Free radical (containing an unpaired electron) and nonradical ROS can be produced through different mechanisms including the plasma or organelle membrane-bound NADPH oxidase (NOX) family of enzymes, ischemia/reperfusion, inflammatory response, transition metal ions, and inefficient electron transport chain reactivity in organelles such as mitochondria. Some ROS such as superoxide anion $\left(\mathrm{O}_{2} \cdot \cdot^{-}\right)$or hydroxyl radicals $(\mathrm{OH} \cdot)$ are extremely unstable, whereas others such as hydrogen peroxide $\left(\mathrm{H}_{2} \mathrm{O}_{2}\right)$ are freely diffusible and relatively long-lived, from nanoseconds to milliseconds (Newsholme et al. 2012). In general, ROS are considered highly reactive molecules as they tend to capture electrons from other molecules (oxidation) and produce other ROS, such as peroxynitrite $\left(\mathrm{ONOO}^{-}\right)$, thiol-based radicals (RS·), and others (Brownlee 2001). Moreover, these unstable molecules can promote DNA damage by reacting with nucleotides, proteins, and especially structural components in the cell such as neutral lipids and phospholipids of the membranes via a process known as lipid peroxidation (propagation step of ROS; Finkel \& Holbrook 2000). Lipid peroxidation changes the fluidity of cell membranes, reduces the capacity to maintain defined ion gradients (e.g. $\mathrm{Na}^{+}$and $\mathrm{K}^{+}$), and also increases membrane permeability. Consequently, lipid peroxidation leads to a loss of intracellular proteins, reduces $\mathrm{Ca}^{2+}$ transport across the cell and endoplasmic reticulum membranes, altering mitochondrial voltage channels, and cell function (Dias \& Griffiths 2014).

It has been well-documented that high glucose, fatty acids, and AGEs can increase intracellular ROS generation

Published by Bioscientifica Ltd 
and induce apoptosis in retinal pericytes (Amano et al. 2002, Yamagishi et al. 2002a,b,c). High glucose and fatty acid levels may overstimulate electron transport activity in the mitochondria, leading to excessive generation of superoxide (Newsholme et al. 2007).

Characterized by increased levels of ROS due to excessive production and slow removal by the antioxidant systems, the phenomenon of oxidative stress has attracted attention in the last decades. The rationale for this scientific interest arises from the fact that oxidative stress, and consequently the change in the intracellular redox state, occurs in several disease mechanisms (Krause $\&$ de Bittencourt 2008, Cruzat et al. 2014), including the complications of diabetes (Newsholme et al. 2007) and aging (Ristow et al. 2009). The detrimental effects of AGEs on pericyte survival and function are mediated via increased ROS generation, which then leads to apoptosis. It has been shown that AGE-modified BSA (AGE-BSA) has the potential to stimulate glucose transport into retinal pericytes followed by an elevation in ROS production therefore provoking cell death. The activation of AGE-sensitive cell surface receptors, such as RAGE, or nonreceptor-dependent pathways may be involved in increasing ROS generation (Schmidt et al. 2001; Fig. 1).

The BCL2 family of proteins are key players in the regulation of apoptosis. The anti-apoptotic members of this family, such as BCL2, inhibit apoptosis by blocking the release of cytochrome $c$ from mitochondria. However, the pro-apoptotic members of this family, including BAX, enhance the release of cytochrome $c$, which subsequently

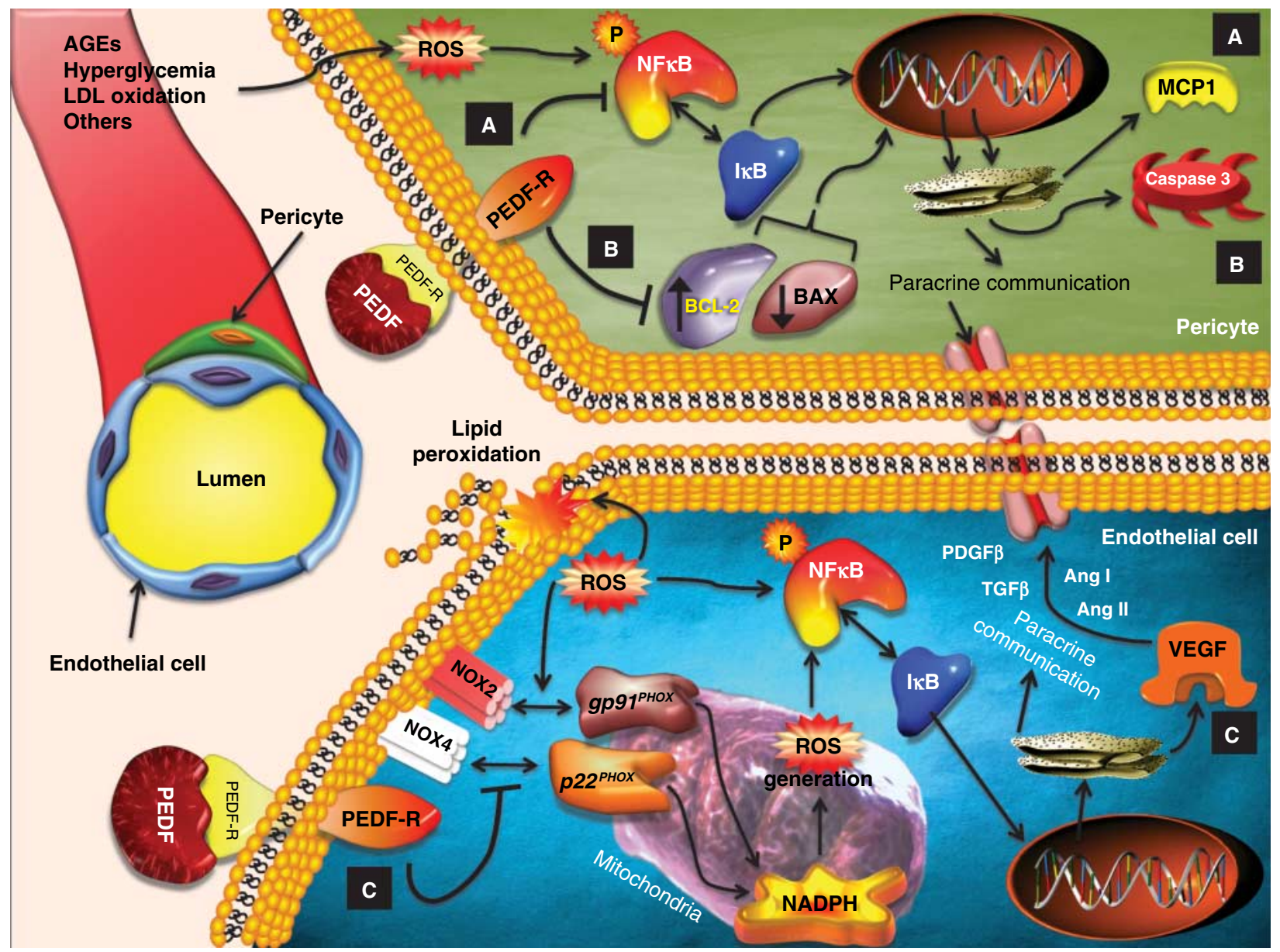

Figure 1

A brief overview of the protective mechanisms mediated by PEDF in conditions of oxidative stress caused by advanced glycation end products (AGEs), NADPH oxidase activation and glycated LDL in pericytes and endothelial cells (EC). (A) In LDL-exposed pericytes, PEDF can suppress the binding of nuclear factor kappa $B(N F \kappa)$ to DNA and, as a result, inhibit the monocyte chemoattractant protein 1 (MCP1) (Zhang et al. 2008).
(B) In AGE-exposed pericytes, PEDF is able to attenuate caspase 3 activity by improving the ratio of BCL2/BAX (Yamagishi et al. 2002a,C). (C) In AGE-exposed EC, PEDF can reduce reactive oxygen species (ROS) generation by downregulating $p^{22 P H O X}$ and $g p 91^{\text {PHOX }}$ thus suppressing NADPH oxidase activity (Yoshida et al. 2009, Yamagishi et al. 2006a). A full colour version of this figure is available at http://dx.doi.org/10.1530/JOE-14-0065.

Published by Bioscientifica Ltd. 
leads to activation of different caspase molecules (such as caspases 3 and 9) that cleave various downstream procaspases within the cell to induce full-blown apoptosis (Cory \& Adams 2002, Broadhead et al. 2009). Furthermore, inflammatory reactions and apoptosis are initiated as a result of activation of MAP kinase/RAS, nuclear factor kappa B (NFкB), AKT, and p38 in addition to key molecules in apoptotic pathways, for example forkhead transcription factors (FOXO) and c-JUN (Min et al. 1999, Alikhani et al. 2007). During pericyte apoptosis, caspase 3 , a key enzyme required for the execution of apoptosis, increases in concentration due to a decreased ratio of BCL2/BAX.

Oxidative stress can result in direct, free radical-based DNA damage, but can also trigger redox pathways required for transcriptional activation. NFאB in retinal pericytes is extremely sensitive to the redox status of the cells, and normally remains in an inactive form, as it is bound with an inhibitory I $\kappa$ B protein. Several inflammatory stimuli, such as TNF $\alpha$, and also elevated levels oxidative stress can promote specific signal transducing pathways to enable phosphorylation of the I $\kappa \mathrm{B}$ and subsequent degradation by the 26 S proteosome (Sethi et al. 2008). The phosphorylation of I $\kappa$ B releases $\mathrm{NF} \kappa \mathrm{B}$ from I $\kappa \mathrm{B}$ protein and permits $\mathrm{NF \kappa B}$ to translocate to the nucleus (Heck et al. 2011). The subunit composition of $\mathrm{NF} \kappa \mathrm{B}$ can vary, although $\mathrm{NF} \kappa \mathrm{B}$ p65

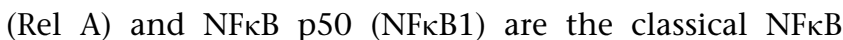
pathway components studied in inflammation (Sethi et al. 2008). Many target genes related to pro-inflammatory

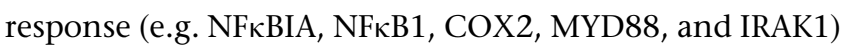
are cyclically activated by $\mathrm{NF} K \mathrm{~B}$. The imbalance

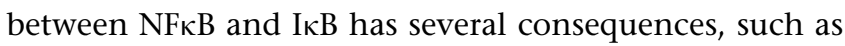
hyper-inflammation and loss of cell repair and function, which lead to apoptosis and DR disease evolution (Duarte et al. 2013).

\section{Summary of the key roles of PEDF and potential mechanisms of protection in oxidative stress conditions}

Apoptosis and PEDF: balance of BCL2 and BAX PEDF has neurotrophic and neuroprotective effects on dopaminergic neurons (Falk et al. 2009), as well as protective effect on pericytes. A dose-dependent effect of PEDF on BCL2 was observed in cultured cortical neurons where PEDF upregulated the expression of BCL2 and promoted neuronal survival against oxidative stress (Sanchez et al. 2012). In photoreceptor cells, the nuclear translocation of apoptosis-inducing factor (AIF) from mitochondria intermembrane space during apoptosis results in chromatin condensation and DNA fragmentation. The upregulation of BCL2 by PEDF leads to inhibition of the nuclear translocation of AIF, resulting in prevention of the apoptosis in both in vitro and in vivo (Murakami et al. 2008). PEDF significantly prevents the arrest of DNA synthesis in cultured AGE-exposed pericytes by reversing the reduction in expression of BCL2, as well as inactivating BAX expression in retinal pericytes and thus aids pericyte survival (Fig. 1; Yamagishi et al. 2002a,c).

PEDF and inflammatory signal transduction The protective effect of PEDF on retinal pericytes exposed to highglucose or $\mathrm{H}_{2} \mathrm{O}_{2}$ is via stimulation of antioxidative mechanisms, such as inhibition of ROS production, and normalizing or enhancing the level of antioxidant enzymes such as phospholipid hydroperoxide/glutathione peroxidase (GSH-Px). PEDF is able to induce and increase the mRNA expression level of GSH-Px (Yamagishi et al. 2002a,c, Amano et al. 2005). However, the role of PEDF in regulating the levels and activity of the other major antioxidant enzymes - catalase and $\mathrm{Cu} / \mathrm{Zn}$ superoxide dismutase (SOD) - has yet to be elucidated. Similarly, JAK2/STAT3 and ERKs (ERK1/2) are activated in bovine retinal capillary ECs (BRECs) (Zheng et al. 2010) and human retinal pigment epithelial cells (ARPE-19) respectively (Tsao et al. 2006). PEDF decreased the level of mitochondria-generated ROS, suppressed JAK2/STAT3 activation, leading to lower VEGF mRNA expression (Zheng et al. 2010). On the contrary, PEDF can induce ERK1/2 phosphorylation and activation and protect ARPE19 cells against $\mathrm{H}_{2} \mathrm{O}_{2}$-mediated oxidative stress (Tsao et al. 2006). Similar pathways are involved in PEDF-mediated protection in cerebellum granule cells (Taniwaki et al. 1995, 1997), hippocampal neurons (DeCoster et al. 1999), and spinal motor neurons (Bilak et al. 1999) against glutamate toxicity. PEDF can induce ERK1/2 phosphorylation followed by phosphorylation and activation of cAMP-responsive element-binding protein (CREB) - the two key molecules in the cell survival signal transduction pathway - therefore providing protective properties in cultured rat cerebellar granule cells (CGCs) (Yabe et al. $2005 b$ ). Interestingly, the protective effect of PEDF has been observed in immature CGCs rather than mature cells (Taniwaki et al. 1995, Araki et al. 1998). The suggested mechanism underlying glutamate neurotoxicity is the elevation of intracellular $\mathrm{Ca}^{2+}$ as a result of opening $\mathrm{N}$-methyl-D-aspartate (NMDA) channels. The high free intracellular $\mathrm{Ca}^{2+}$ leads to activation of $\mathrm{Ca}^{2+}$-dependent enzymes - nucleases, proteases, protein kinases, and protein phosphatases - and may also lead to the generation of free radicals. It has been postulated that PEDF can block the initial signal transduction, which leads

Published by Bioscientifica Ltd. 
to the opening of NMDA channels as well as maintain $\mathrm{Ca}^{2+}$ homeostasis through removal of excess $\mathrm{Ca}^{2+}$, thus helping cell survival (Taniwaki et al. 1997).

As mentioned before NFKB is one of the transcription factors activated during oxidative stress. PEDF inhibition of this particular pathway results in protection for AGEexposed mesangial cells. In this situation, the coupling of RAGE and AGE can initiate downstream signaling and stimulate ROS-generated inflammatory and thrombogenic reactions via redox-sensitive transcriptional factor NFKB. PEDF can inhibit ROS generation, attenuating NFкB activation and subsequently inhibiting the expression of inflammatory and thrombogenic genes such as monocyte chemoattractant protein 1 (MCP1), vascular cell adhesion molecule 1 (VCAM1), and plasminogen activator inhibitor 1 (PAI1) (Ide et al. 2010). Furthermore, there is a correlation between MCP1 protein abundance in vitreous fluids and progression of proliferative DR (Mitamura et al. 2001). However, PEDF can inhibit AGE-induced overexpression of MCP1 in ECs by suppressing the generation of intracellular ROSs (Inagaki et al. 2003). This may be similar to the situation in retinal pericytes when exposed to glycated LDL. This oxidizing factor could activate the NFKB pathway and lead to overexpression of MCP1. PEDF has an inhibitory effect on MCP1 expression, which consequently results in decreased cell permeability and leakage and ultimately neovascularization in DR (Fig. 1). It also has been shown that PEDF can suppress the binding of NFKB to DNA and its transcription activation in a celltype-specific manner (Yabe et al. 2001, Zhang et al. 2008). Production of pro-inflammatory cytokines can be inhibited by the activation of NFKB or CREB in cultured microglia (Sanagi et al. 2005), neonatal astrocytes (Yabe et al. 2005a), and rat culture CGCs (Yabe et al. 2005b). PEDF regulates the level of these transcription factors and therefore acts as a neuroimmune modulator in the CNS (Sanagi et al. 2005).

In relation to AGE-induced apoptosis in podocytes (epithelial cells around glomerular capillaries), restoration of transcriptional activity of peroxisome proliferatoractivated receptor gamma (PPAR $\gamma$ ) is the proposed pathway for PEDF protection, although it did not affect the AGE-induced reduction in PPAR $\gamma$ protein expression (Ishibashi et al. 2013). The antagonist effect of PEDF/RAGE also contributes to activation of PPAR $\gamma$ therefore inhibiting generation of ROS. PPAR $\gamma$ activation by PEDF can inhibit platelet-derived growth factor (PDGF)-induced migration and proliferation of smooth muscle cell (SMC) as well as suppress macrophage-mediated inflammatory reactions (Yang et al. 2010, Wang et al. 2012) which ultimately would lead to atherosclerosis as a result of ROS-induced signal transduction involving angiotensin II mediated EC activation and SMC proliferation (Nishikawa et al. 2000, Sorescu et al. 2002).

PEDF and NADPH NOX-mediated ROS production and initiation of the redox-dependent signaling cascade as a result of Ang II expression and stimulation is an important event in vascular injury and inflammation (Yamagishi et al. 2005). PEDF can inhibit NOX ROS generation and in the case of MOLT-3 T cells, an immortalized T cell line, it leads to blocking and suppressing Ang II-induced VEGF expression (Yamagishi et al. 2006a). The protective effect of PEDF via its antioxidative effect has also been observed in Ang II-exposed human umbilical vein ECs (HUVECs). The activation of redox-sensitive transcription factor $\mathrm{NF \kappa B}$, and as a result, overexpression of MCP1 in HUVECs, is induced by activation of Ang II. PEDF can protect HUVECs via downregulation of the mRNA level of $p 22^{\text {PHOX }}$ associated with NOX 4 and $g p 91^{\text {PHOX }}$ associated with NOX2. These subunits are membrane-bound components of NOX. A reduction in the level of these proteins can inhibit Ang II-induced ROS production (Yamagishi et al. 2005).

Studies on vascular hyperpermeability and oxidative stress in retinal ECs also include examination of the role of NOX and its various membrane components. NOX will be critical to superoxide and subsequently $\mathrm{H}_{2} \mathrm{O}_{2}$ generation (via SOD) in PEDF-stimulated ECs (Fig. 1). Some findings suggest that PEDF has an inhibitory effect on AGEmediated VEGF-induced vascular hyperpermeability via suppression of VEGF expression (Yamagishi et al. 2006b, Yoshida et al. 2009). The latter authors have also shown that NOX activity has an important role in elevating ROS generation and ultimately in apoptosis and increased cell permeability. PEDF can downregulate $p^{22 P H O X}$ and $g p 91^{\text {PHOX }}$ mRNA levels and subsequently suppress NOX protein levels and activity (Yamagishi et al. 2006b, 2007b, Yoshida et al. 2009). Reduced NOX activity inhibits NFאBdependent VEGF expression in ECs, affecting EC's vascular lining permeability and inhibiting ROS generation (Fig. 1). Furthermore, PEDF also has a protective effect in $\mathrm{H}_{2} \mathrm{O}_{2}$ induced retinal pigment epithelium (RPE) permeability. It has been shown that in $\mathrm{H}_{2} \mathrm{O}_{2}$-induced oxidative stress, PEDF is able to suppress the stress-activated p38/MAPK signaling pathway by inhibiting the phosphorylation and activation of a key substrate (HSP27; Ho et al. 2006). In a leptin-induced ROS generation model, PEDF inhibited VEGF expression, thus potentially eliminating the

Published by Bioscientifica Ltd 

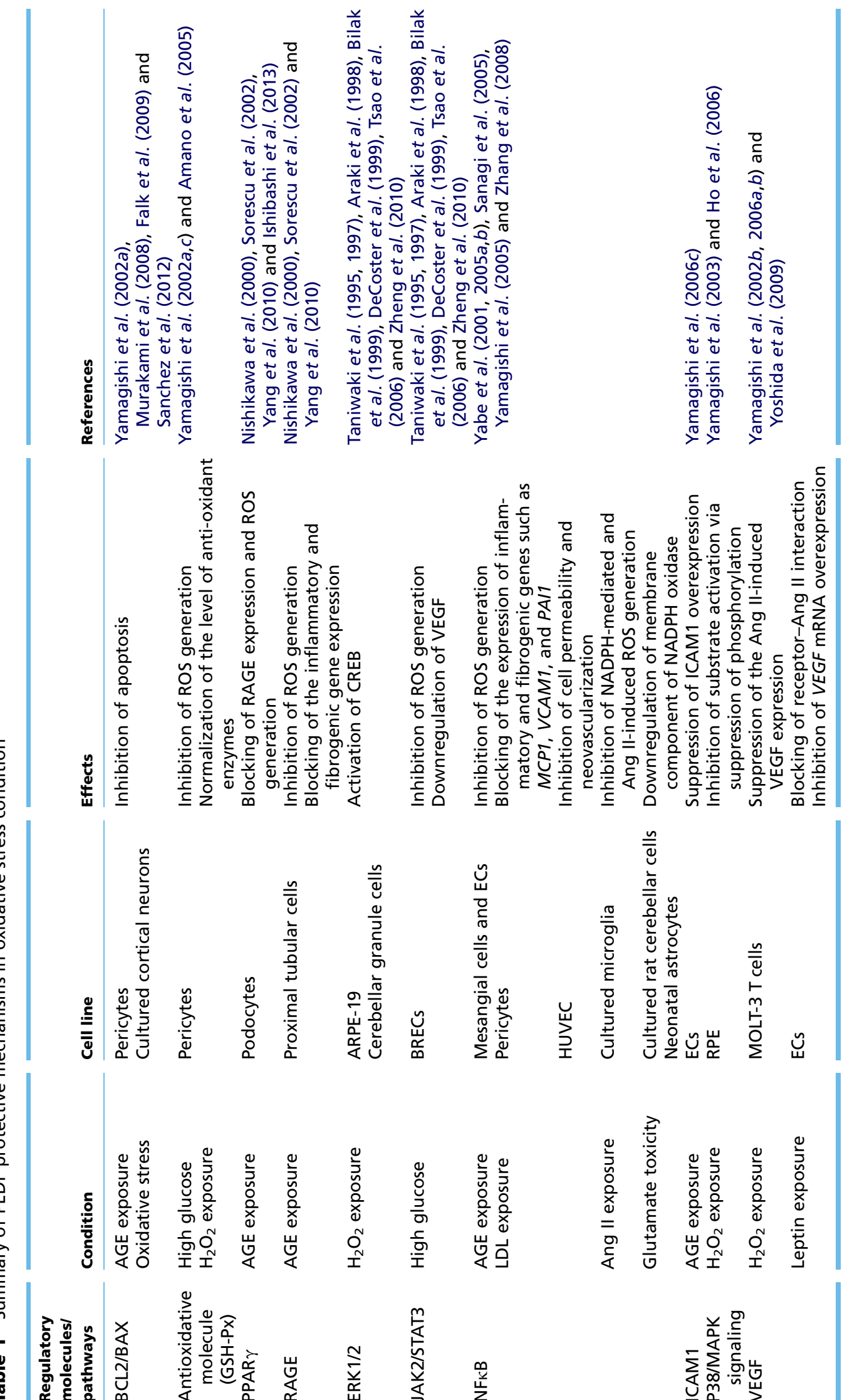
angiogenic effect of leptin and protecting ECs through its antioxidant properties (Yamagishi et al. 2003).

Adhesion of leukocytes and inflammatory cells to the capillary endothelium (leukostasis) is one of the possible mechanisms of DR, which can be related to ICAM1 levels. In AGE-induced oxidative stress conditions, ICAM1 overexpression may result in retinal leukostasis. PEDF can inhibit the overexpression of ICAM1 in ECs via its antioxidative properties (Yamagishi et al. 2006c).

Table 1 summarizes the suggested mechanisms of PEDF action in various cell types and PEDF-mediated survival in oxidative stress conditions.

\section{Pericyte-EC communication and PEDF}

The communication system between pericytes and ECs during angiogenesis and maturation of the vasculature system consists of several complex paracrine signaling pathways such as PDGF $\beta$, activated transforming growth factor beta, VEGF, angiopoietin 1 (Ang I), and its antagonist angiopoietin 2 (Ang II) (Milne \& Brownstein 2013). The regulatory effect of PEDF on paracrine signaling and its role in the maintenance of homeostasis between pericytes and ECs are also dependent on the antioxidative function of PEDF. Platelet activation and aggregation is a common cause of vascular complications in diabetic patients and oxidative stress via the action of AGEs (Yamagishi et al. 2001). The antioxidative activity of PEDF can reduce the production of NOX-driven superoxide, and can inhibit platelet activation and aggregation as well as have a detrimental effect on AGEs in diabetic rat models (Yamagishi et al. 2009).

Moreover, both in vivo and in vitro hyperglycemic conditions can result in activation of NFKB in retinal pericytes which can upregulate BAX and TNF $\alpha$ (Romeo et al. 2002). Ang I has a protective effect on pericytes in such conditions; however, Ang II accelerates TNF $\alpha$ - and hyperglycemia-induced apoptosis as well as pericyte migration from retinal capillaries, which lead to pericyte loss and EC proliferation (Cai et al. 2008, Pfister et al. 2008). In a high-glucose ROS-induced condition, the mRNA ratio of Ang II to Ang I increases and consequently elevates the VEGF mRNA level in pericytes (Amano et al. 2005). This may disrupt pericyte-EC interactions and induce angiogenesis-related gene expression. Through its antioxidative properties, PEDF can inhibit pericyte apoptosis, modifying VEGF-mediated gene expression and ultimately delaying or even halting the progression of DR (Amano et al. 2005).

\section{Clinical implications and possible future studies}

In the normal adult eye (especially in macular region), the concentration of PEDF is tenfold higher than VEGF, which may suggest that PEDF is the main factor responsible for the low number of blood vessels associated with macular avascularity (Kociok \& Joussen 2007, Kozulin et al. 2010). However, the level of PEDF in the vitreous of the eye in patients suffering from proliferative diseases such as PDR is significantly lower than in the normal eye, which may be a biomarker of oxidative stress in the eye, and the pharmacological upregulation or administration of PEDF may be a therapeutic strategy to address PDR (Yokoi et al. 2007). The imbalanced ratio of VEGF and PEDF bring the concept of anti-angiogenic therapy into perspective. Anti-VEGF antibodies have been used clinically and showed significant positive results, but the efficacy is limited by short half-life (10 days). Therefore, to maintain the therapeutic effect, regular dosing is required, although repetitive injections carry substantial risks for the patient, such as retinal detachment, endophthalmitis, cataract formation, ocular hypertension, and submacular hemorrhage. In this approach, using PEDF (a potent anti-angiogenic molecule) seems a promising strategy. However, the short half-life is still an issue. In this regard, some new delivery systems have been tested in order to increase the efficiency of delivery and half-life of the PEDF gene therapy method. The examples include adeno-associated virus vector-mediated PEDF delivery, which has been recently described (Streck et al. 2005, Park et al. 2011, He et al. 2012). However, because of its potential carcinogenic properties, immunogenicity, uncertain quantitative expression, and lower production rate, this application is limited for therapy. Other studies have also used poly(D,L-lactide-coglycolide acid) nanoparticles for efficient PEDF gene delivery, but processing and formulation lead to loss of activity of PEDF (Pai et al. 2009). Polyethylene glycol is a polyether with many applications in medicine and has recently been used to improve the pharmacokinetic and pharmacodynamic properties of administered PEDF. This strategy provided promising results for long-term therapy of PDR as well as other retinal angiogenic diseases (Bai et al. 2012).

\section{Conclusion}

Pericytes and ECs respond in different ways to oxidative stress. AGE-induced ROS inhibits the growth of pericytes. Oxidative stress commonly occurs in chronic diseases such as diabetes mellitus, thus PEDF could protect retinal

Published by Bioscientifica Ltd 
pericytes exposed to such stress through its antioxidative properties as well as through inhibition of EC activation. PEDF may act directly on ECs to prevent inflammationmediated pro-proliferative responses, therefore playing a protective role against angiogenesis. Furthermore, PEDF could affect or upregulate anti-apoptotic gene expression in neural cells that can improve neuronal survival. Taken together, PEDF is emerging as a novel and suitable candidate for new therapeutic approaches in neurodegenerative disorders and vascular complications in diseases such as diabetes mellitus.

\section{Declaration of interest}

The authors declare that there is no conflict of interest that could be perceived as prejudicing the impartiality of this review.

\section{Funding}

$M E$ is supported by an IPR Scholarship from Victoria University and CRD by a Curtin Academic50 scheme. V F C is supported by Brazilian National Council for Scientific and Technological Development (CNPq)/Science without borders Programme (process 245562/2012-5). P N is supported by the School of Biomedical Sciences and Faculty of Health Sciences with respect to diabetes and metabolism research at Curtin University.

\section{Author contribution statement}

$M E$ and $C D$ designed the outline of the review, and $M E$ was responsible for writing the first draft of this review. S B-H, V F C, P N, and C D were responsible for subsequent revisions to the manuscript. All authors approved the final version of the manuscript.

\section{References}

Alikhani M, MacLellan CM, Raptis M, Vora S, Trackman PC \& Graves DT 2007 Advanced glycation end products induce apoptosis in fibroblasts through activation of ROS, MAP kinases, and the FOXO1 transcription factor. American Journal of Physiology. Cell Physiology 292 C850-C856. (doi:10.1152/ajpcell.00356.2006)

Amano S, Yamagishi SI, Kato N, Inagaki Y, Okamoto T, Makino M, Taniko K, Hirooka H, Jomori T \& Takeuchi M 2002 Sorbitol dehydrogenase overexpression potentiates glucose toxicity to cultured retinal pericytes. Biochemical and Biophysical Research Communications 299 183-188. (doi:10.1016/S0006-291X(02)02584-6)

Amano S, Yamagishi SI, Inagaki Y, Nakamura K, Takeuchi M, Inoue H \& Imaizumi T 2005 Pigment epithelium-derived factor inhibits oxidative stress-induced apoptosis and dysfunction of cultured retinal pericytes. Microvascular Research 69 45-55. (doi:10.1016/j.mvr.2004.11.001)

Araki T, Taniwaki T, Becerra SP, Chader GJ \& Schwartz JP 1998 Pigment epithelium-derived factor (PEDF) differentially protects immature but not mature cerebellar granule cells against apoptotic cell death. Journal of Neuroscience Research 53 7-15. (doi:10.1002/(SICI)10974547(19980701)53:1\%3C;7::AID-JNR2\%3E;3.0.CO;2-F)

Bai Y-J, Huang L-Z, Xu X-L, Du W, Zhou A-Y, Yu W-Z \& Li X-X 2012 Polyethylene glycol-modified pigment epithelial-derived factor: new prospects for treatment of retinal neovascularization. Journal of

http://joe.endocrinology-journals.org DOI: $10.1530 /$ JOE-14-0065
() 2014 Society for Endocrinology Printed in Great Britain
Pharmacology and Experimental Therapeutics 342 131-139. (doi:10.1124/ jpet.112.192575)

Bilak MM, Corse AM, Bilak SR, Lehar M, Tombran-Tink J \& Kuncl RW 1999 Pigment epithelium-derived factor (PEDF) protects motor neurons from chronic glutamate-mediated neurodegeneration. Journal of Neuropathology and Experimental Neurology 58 719-728. (doi:10.1097/ 00005072-199907000-00006)

Boehm BO, Lang G, Volpert O, Jehle PM, Kurkhaus A, Rosinger S, Lang GK $\&$ Bouck N 2003 Low content of the natural ocular anti-angiogenic agent pigment epithelium-derived factor (PEDF) in aqueous humor predicts progression of diabetic retinopathy. Diabetologia 46 394-400.

Broadhead ML, Dass CR \& Choong PFM 2009 Cancer cell apoptotic pathways mediated by PEDF: prospects for therapy. Trends in Molecular Medicine 15 461-467. (doi:10.1016/j.molmed.2009.08.003)

Brownlee M 2001 Biochemistry and molecular cell biology of diabetic complications. Nature 414 813-820. (doi:10.1038/414813a)

Cai J, Kehoe O, Smith GM, Hykin P \& Boulton ME 2008 The angiopoietin/Tie-2 system regulates pericyte survival and recruitment in diabetic retinopathy. Investigative Ophthalmology \& Visual Science 49 2163-2171. (doi:10.1167/iovs.07-1206)

Cory S \& Adams JM 2002 The BCL2 family: regulators of the cellular life-or-death switch. Nature Reviews. Cancer 2 647-656. (doi:10.1038/ nrc883)

Cruzat VF, Pantaleao LC, Donato J Jr, de Bittencourt PI Jr \& Tirapegui J 2014 Oral supplementations with free and dipeptide forms of L-glutamine in endotoxemic mice: effects on muscle glutamine-glutathione axis and heat shock proteins. Journal of Nutritional Biochemistry 25 345-352. (doi:10.1016/j.jnutbio.2013.11.009)

Dass CR, Contreras KG, Dunstan DE \& Choong PF 2007 Chitosan microparticles encapsulating PEDF plasmid demonstrate efficacy in an orthotopic metastatic model of osteosarcoma. Biomaterials $\mathbf{2 8}$ 3026-3033. (doi:10.1016/j.biomaterials.2007.03.016)

DeCoster MA, Schabelman E, Tombran-Tink J \& Bazan NG 1999 Neuroprotection by pigment epithelial-derived factor against glutamate toxicity in developing primary hippocampal neurons. Journal of Neuroscience Research 56 604-610. (doi:10.1002/(SICI) 1097-4547(19990615)56:6\%3C;604::AID-JNR6\%3E;3.0.CO;2-B)

Dias IH \& Griffiths HR 2014 Oxidative stress in diabetes - circulating advanced glycation end products, lipid oxidation and vascular disease. Annals of Clinical Biochemistry 51 125-127. (doi:10.1177/ 0004563213508747)

Duarte DA, Silva KC, Rosales MA, Lopes de Faria JB \& Lopes de Faria JM 2013 The concomitance of hypertension and diabetes exacerbating retinopathy: the role of inflammation and oxidative stress. Current Clinical Pharmacology 8 266-277. (doi:10.2174/1574884711308040002)

Ejaz S 2008 Importance of pericytes and mechanisms of pericyte loss during diabetes retinopathy. Diabetes, Obesity \& Metabolism 10 53-63.

Ek ET, Dass CR, Contreras KG \& Choong PF 2007a Inhibition of orthotopic osteosarcoma growth and metastasis by multitargeted antitumor activities of pigment epithelium-derived factor. Clinical \& Experimental Metastasis 24 93-106. (doi:10.1007/s10585-007-9062-1)

Ek ET, Dass CR, Contreras KG \& Choong PF 2007b Pigment epitheliumderived factor overexpression inhibits orthotopic osteosarcoma growth, angiogenesis and metastasis. Cancer Gene Therapy 14 616-626. (doi:10.1038/sj.cgt.7701044)

Ek ET, Dass CR, Contreras KG \& Choong PF 2007c PEDF-derived synthetic peptides exhibit antitumor activity in an orthotopic model of human osteosarcoma. Journal of Orthopaedic Research 25 1671-1680. (doi:10.1002/jor.20434)

Falk T, Zhang S \& Sherman SJ 2009 Pigment epithelium derived factor (PEDF) is neuroprotective in two in vitro models of Parkinson's disease. Neuroscience Letters 458 49-52. (doi:10.1016/j.neulet.2009.04.018)

Filiz G \& Dass CR 2012 Reduction in tumour cell invasion by pigment epithelium-derived factor is mediated by membrane type- 1 matrix metalloproteinase downregulation. Die Pharmazie 67 1010-1014. 
Finkel T \& Holbrook NJ 2000 Oxidants, oxidative stress and the biology of ageing. Nature 408 239-247. (doi:10.1038/35041687)

Fukami K, Ueda S, Yamagishi SI, Kato S, Inagaki Y, Takeuchi M, Motomiya Y, Bucala R, Iida S, Tamaki K et al. 2004 AGEs activate mesangial TGF$\beta$-Smad signaling via an angiotensin II type I receptor interaction. Kidney International 66 2137-2147. (doi:10.1111/j.1523-1755.2004. 66004.x)

Hammes HP 2005 Pericytes and the pathogenesis of diabetic retinopathy. Hormone and Metabolic Research 37 S39-S43. (doi:10.1055/s-2005861361)

Hammes HP, Alt A, Niwa T, Clausen JT, Bretzel RG, Brownlee M \& Schleicher ED 1999 Differential accumulation of advanced glycation end products in the course of diabetic retinopathy. Diabetologia 42 728-736. (doi:10.1007/s001250051221)

He SS, Shi HS, Yin T, Li YX, Luo ST, Wu QJ, Lu L, Wei YQ \& Yang L 2012 AAV-mediated gene transfer of human pigment epithelium-derived factor inhibits Lewis lung carcinoma growth in mice. Oncology Reports 27 1142-1148.

Heck TG, Scholer CM \& de Bittencourt PI 2011 HSP70 expression: does it a novel fatigue signalling factor from immune system to the brain? Cell Biochemistry and Function 29 215-226. (doi:10.1002/cbf.1739)

Ho TC, Yang YC, Cheng HC, Wu AC, Chen SL \& Tsao YP 2006 Pigment epithelium-derived factor protects retinal pigment epithelium from oxidant-mediated barrier dysfunction. Biochemical and Biophysical Research Communications 342 372-378. (doi:10.1016/j.bbrc.2006. 01.164)

Ide Y, Matsui T, Ishibashi Y, Takeuchi M \& Yamagishi SI 2010 Pigment epithelium-derived factor inhibits advanced glycation end product-elicited mesangial cell damage by blocking NF- $\mathrm{B}$ activation. Microvascular Research 80 227-232. (doi:10.1016/j.mvr.2010.03.015)

Inagaki Y, Yamagishi S, Okamoto T, Takeuchi M \& Amano S 2003 Pigment epithelium-derived factor prevents advanced glycation end products-induced monocyte chemoattractant protein-1 production in microvascular endothelial cells by suppressing intracellular reactive oxygen species generation. Diabetologia 46 284-287.

Ishibashi Y, Matsui T, Ohta K, Tanoue R, Takeuchi M, Asanuma K, Fukami K, Okuda S, Nakamura KI \& Yamagishi SI 2013 PEDF inhibits AGE-induced podocyte apoptosis via PPAR- $\gamma$ activation. Microvascular Research $\mathbf{8 5}$ 54-58. (doi:10.1016/j.mvr.2012.10.007)

Kociok N \& Joussen A 2007 Varied expression of functionally important genes of RPE and choroid in the macula and in the periphery of normal human eyes. Graefe's Archive for Clinical and Experimental Ophthalmology 245 101-113. (doi:10.1007/s00417-006-0266-x)

Kozulin P, Natoli R, Bumsted O’Brien KM, Madigan MC \& Provis JM 2010 The cellular expression of antiangiogenic factors in fetal primate macula. Investigative Ophthalmology \& Visual Science $514298-4306$. (doi:10.1167/iovs.09-4905)

Krause MS \& de Bittencourt PI Jr 2008 Type 1 diabetes: can exercise impair the autoimmune event? The L-arginine/glutamine coupling hypothesis Cell Biochemistry and Function 26 406-433. (doi:10.1002/cbf.1470)

Milne R \& Brownstein S 2013 Advanced glycation end products and diabetic retinopathy. Amino Acids 44 1397-1407. (doi:10.1007/s00726011-1071-3)

Min C, Kang E, Yu SH, Shinn SH \& Kim YS 1999 Advanced glycation end products induce apoptosis and procoagulant activity in cultured human umbilical vein endothelial cells. Diabetes Research and Clinical Practice 46 197-202. (doi:10.1016/S0168-8227(99)00094-7)

Mitamura Y, Takeuchi S, Matsuda A, Tagawa Y, Mizue Y \& Nishihira J 2001 Monocyte chemotactic protein-1 in the vitreous of patients with proliferative diabetic retinopathy. Ophthalmologica 215 415-418. (doi:10.1159/000050900)

Murakami Y, Ikeda Y, Yonemitsu Y, Onimaru M, Nakagawa K, Kohno R, Miyazaki M, Hisatomi T, Nakamura M, Yabe T et al. 2008 Inhibition of nuclear translocation of apoptosis-inducing factor is an essential mechanism of the neuroprotective activity of pigment epithelium-derived factor in a rat model of retinal degeneration.

http://joe.endocrinology-journals.org DOI: 10.1530/JOE-14-0065 (c) 2014 Society for Endocrinology Printed in Great Britain
American Journal of Pathology 173 1326-1338. (doi:10.2353/ajpath. 2008.080466)

Nakamura K, Yamagishi SI, Matsui T, Yoshida T, Takenaka K, Jinnouchi Y, Yoshida Y, Ueda SI, Adachi H \& Imaizumi T 2007 Pigment epitheliumderived factor inhibits neointimal hyperplasia after vascular injury by blocking NADPH oxidase-mediated reactive oxygen species generation. American Journal of Pathology 170 2159-2170. (doi:10.2353/ajpath. 2007.060838)

Newsholme P, Haber EP, Hirabara SM, Rebelato EL, Procopio J, Morgan D, Oliveira-Emilio HC, Carpinelli AR \& Curi R 2007 Diabetes associated cell stress and dysfunction: role of mitochondrial and non-mitochondrial ROS production and activity. Journal of Physiology 583 9-24. (doi:10.1113/jphysiol.2007.135871)

Newsholme P, Rebelato E, Abdulkader F, Krause M, Carpinelli A \& Curi R 2012 Reactive oxygen and nitrogen species generation, antioxidant defenses, and $\beta$-cell function: a critical role for amino acids. Journal of Endocrinology 214 11-20. (doi:10.1530/JOE-12-0072)

Nishikawa T, Edelstein D, Du XL, Yamagishi SI, Matsumura T, Kaneda Y, Yorek MA, Beebe D, Oates PJ, Hammes HP et al. 2000 Normalizing mitochondrial superoxide production blocks three pathways of hyperglycaemic damage. Nature 404 787-790. (doi:10.1038/35008121)

Pai S, Tilton R \& Przybycien T 2009 Poly(ethylene glycol)-modified proteins: implications for poly(lactide-co-glycolide)-based microsphere delivery. AAPS Journal 11 88-98. (doi:10.1208/s12248-009-9081-8)

Park K, Jin J, Hu Y, Zhou K \& Ma JX 2011 Overexpression of pigment epithelium-derived factor inhibits retinal inflammation and neovascularization. American Journal of Pathology 178 688-698. (doi:10.1016/j.ajpath.2010.10.014)

Pfister F, Feng Y, Hagen FV, Hoffmann S, Molema G, Hillebrands JL, Shani M, Deutsch U \& Hammes HP 2008 Pericyte migration: a novel mechanism of pericyte loss in experimental diabetic retinopathy. Diabetes 57 2495-2502. (doi:10.2337/db08-0325)

Ristow M, Zarse K, Oberbach A, Kloting N, Birringer M, Kiehntopf M, Stumvoll M, Kahn CR \& Bluher M 2009 Antioxidants prevent health-promoting effects of physical exercise in humans. PNAS 106 8665-8670. (doi:10.1073/pnas.0903485106)

Romeo G, Liu WH, Asnaghi V, Kern TS \& Lorenzi M 2002 Activation of nuclear factor- $\kappa \mathrm{B}$ induced by diabetes and high glucose regulates a proapoptotic program in retinal pericytes. Diabetes $512241-2248$. (doi:10.2337/diabetes.51.7.2241)

Sanagi T, Yabe T \& Yamada H 2005 The regulation of pro-inflammatory gene expression induced by pigment epithelium-derived factor in rat cultured microglial cells. Neuroscience Letters 380 105-110. (doi:10.1016/j.neulet.2005.01.035)

Sanchez A, Tripathy D, Yin X, Luo J, Martinez J \& Grammas P 2012 Pigment epithelium-derived factor (PEDF) protects cortical neurons in vitro from oxidant injury by activation of extracellular signal-regulated kinase (ERK) $1 / 2$ and induction of Bcl-2. Neuroscience Research 72 1-8. (doi:10.1016/j.neures.2011.09.003)

Sato T, Iwaki M, Shimogaito N, Wu X, Yamagishi SI \& Takeuchi M 2006 TAGE (toxic AGEs) theory in diabetic complications. Current Molecular Medicine 6 351-358. (doi:10.2174/156652406776894536)

Schmidt AM, Yan SD, Yan SF \& Stern DM 2001 The multiligand receptor RAGE as a progression factor amplifying immune and inflammatory responses. Journal of Clinical Investigation 108 949-955. (doi:10.1172/ JCI200114002)

Sethi G, Sung B \& Aggarwal BB 2008 Nuclear factor- $\kappa$ B activation: from bench to bedside. Experimental Biology and Medicine 233 21-31. (doi:10.3181/0707-MR-196)

Sorescu D, Weiss D, Lassègue B, Clempus RE, Szöcs K, Sorescu GP, Valppu L, Quinn MT, Lambeth JD, Vega JD et al. 2002 Superoxide production and expression of Nox family proteins in human atherosclerosis. Circulation 105 1429-1435. (doi:10.1161/01.CIR.0000012917.74432.66)

Streck CJ, Zhang Y, Zhou J, Ng C, Nathwani AC \& Davidoff AM 2005 Adeno-associated virus vector-mediated delivery of pigment epithelium-derived factor restricts neuroblastoma angiogenesis and 
growth. Journal of Pediatric Surgery 40 236-243. (doi:10.1016/j.jpedsurg. 2004.09.049)

Ta HT, Dass CR, Larson I, Choong PF \& Dunstan DE 2009 A chitosan hydrogel delivery system for osteosarcoma gene therapy with pigment epithelium-derived factor combined with chemotherapy. Biomaterials 30 4815-4823. (doi:10.1016/j.biomaterials.2009.05.035)

Tan ML, Choong PF \& Dass CR 2010 Anti-chondrosarcoma effects of PEDF mediated via molecules important to apoptosis, cell cycling, adhesion and invasion. Biochemical and Biophysical Research Communications 398 613-618. (doi:10.1016/j.bbrc.2010.05.098)

Taniwaki T, Becerra SP, Chader GJ \& Schwartz JP 1995 Pigment epitheliumderived factor is a survival factor for cerebellar granule cells in culture. Journal of Neurochemistry 64 2509-2517. (doi:10.1046/j.1471-4159. 1995.64062509.x)

Taniwaki T, Hirashima N, Becerra SP, Chader GJ, Etcheberrigaray R \& Schwartz JP 1997 Pigment epithelium-derived factor protects cultured cerebellar granule cells against glutamate-induced neurotoxicity. Journal of Neurochemistry 68 26-32. (doi:10.1046/j.1471-4159.1997. 68010026.x)

Tsao YP, Ho TC, Chen SL \& Cheng HC 2006 Pigment epithelium-derived factor inhibits oxidative stress-induced cell death by activation of extracellular signal-regulated kinases in cultured retinal pigment epithelial cells. Life Sciences 79 545-550. (doi:10.1016/j.lfs.2006.01.041)

Wang SH, Liang CJ, Wu JC, Huang JJ, Chien HF, Tsai JS, Yen YS, Tseng YC, Lue JH \& Chen YL 2012 Pigment epithelium-derived factor reduces the PDGF-induced migration and proliferation of human aortic smooth muscle cells through PPAR $\gamma$ activation. International Journal of Biochemistry \& Cell Biology 44 280-289. (doi:10.1016/j.biocel.2011.10.023)

Yabe T, Wilson D \& Schwartz JP $2001 \mathrm{NF} \kappa \mathrm{B}$ activation is required for the neuroprotective effects of pigment epithelium-derived factor (PEDF) on cerebellar granule neurons. Journal of Biological Chemistry $\mathbf{2 7 6}$ 43313-43319. (doi:10.1074/jbc.M107831200)

Yabe T, Sanagi T, Schwartz JP \& Yamada H 2005 a Pigment epitheliumderived factor induces pro-inflammatory genes in neonatal astrocytes through activation of NF- $\kappa$ B and CREB. Glia 50 223-234. (doi:10.1002/ glia.20171)

Yabe T, Kanemitsu K, Sanagi T, Schwartz JP \& Yamada H 2005b Pigment epithelium-derived factor induces pro-survival genes through cyclic AMP-responsive element binding protein and nuclear factor $\kappa \mathrm{B}$ activation in rat cultured cerebellar granule cells: Implication for its neuroprotective effect. Neuroscience 133 691-700. (doi:10.1016/j. neuroscience.2005.03.007)

Yamagishi S \& Matsui T 2011 Advanced glycation end products (AGEs), oxidative stress and diabetic retinopathy. Current Pharmaceutical Biotechnology 12 362-368. (doi:10.2174/138920111794480534)

Yamagishi SI, Hsu CC, Kobayashi KI \& Yamamoto H $1993 a$ Endothelin 1 mediates endothelial cell-dependent proliferation of vascular pericytes. Biochemical and Biophysical Research Communications 191 840-846. (doi:10.1006/bbrc.1993.1293)

Yamagishi SI, Kobayashi KI \& Yamamoto H 1993b Vascular pericytes not only regulate growth, but also preserve prostacyclin-producing ability and protect against lipid peroxide-induced injury of co-cultured endothelial cells. Biochemical and Biophysical Research Communications 190 418-425. (doi:10.1006/bbrc.1993.1064)

Yamagishi SI, Edelstein D, Du XL \& Brownlee M 2001 Hyperglycemia potentiates collagen-induced platelet activation through mitochondrial superoxide overproduction. Diabetes 50 1491-1494. (doi:10.2337/diabetes.50.6.1491)

Yamagishi SI, Inagaki Y, Amano S, Okamoto T, Takeuchi M \& Makita Z $2002 a$ Pigment epithelium-derived factor protects cultured retinal pericytes from advanced glycation end product-induced injury through its antioxidative properties. Biochemical and Biophysical Research Communications 296 877-882. (doi:10.1016/S0006-291X(02)00940-3)

Yamagishi SI, Amano S, Inagaki Y, Okamoto T, Koga K, Sasaki N, Yamamoto H, Takeuchi M \& Makita Z 2002b Advanced glycation end products-induced apoptosis and overexpression of vascular endothelial

http://joe.endocrinology-journals.org DOI: 10.1530/JOE-14-0065
(C) 2014 Society for Endocrinology Printed in Great Britain growth factor in bovine retinal pericytes. Biochemical and Biophysical Research Communications 290 973-978. (doi:10.1006/bbrc.2001.6312)

Yamagishi SI, Okamoto T, Amano S, Inagaki Y, Koga K, Koga M, Choei H, Sasaki N, Kikuchi S, Takeuchi M et al. 2002c Palmitate-induced apoptosis of microvascular endothelial cells and pericytes. Molecular Medicine 8 179-184.

Yamagishi SI, Amano S, Inagaki Y, Okamoto T, Takeuchi M \& Inoue H 2003 Pigment epithelium-derived factor inhibits leptin-induced angiogenesis by suppressing vascular endothelial growth factor gene expression through anti-oxidative properties. Microvascular Research 65 186-190. (doi:10.1016/S0026-2862(03)00005-0)

Yamagishi SI, Nakamura K, Ueda S, Kato S \& Imaizumi T 2005 Pigment epithelium-derived factor (PEDF) blocks angiotensin II signaling in endothelial cells via suppression of NADPH oxidase: a novel anti-oxidative mechanism of PEDF. Cell and Tissue Research 320 437-445. (doi:10.1007/s00441-005-1094-8)

Yamagishi SI, Matsui T, Nakamura K, Yoshida T, Shimizu K, Takegami Y, Shimizu T, Inoue H \& Imaizumi T 2006 a Pigment-epithelium-derived factor (PEDF) inhibits angiotensin-II-induced vascular endothelial growth factor (VEGF) expression in MOLT-3 T cells through antioxidative properties. Microvascular Research 71 222-226. (doi:10.1016/ j.mvr.2006.03.001)

Yamagishi SI, Nakamura K, Matsui T, Inagaki Y, Takenaka K, Jinnouchi Y, Yoshida Y, Matsuura T, Narama I, Motomiya Y et al. 2006b Pigment epithelium-derived factor inhibits advanced glycation end productinduced retinal vascular hyperpermeability by blocking reactive oxygen species-mediated vascular endothelial growth factor expression. Journal of Biological Chemistry 281 20213-20220. (doi:10.1074/jbc.M602110200)

Yamagishi SI, Matsui T, Nakamura K, Takeuchi M \& Imaizumi T $2006 c$ Pigment epithelium-derived factor (PEDF) prevents diabetes- or advanced glycation end products (AGE)-elicited retinal leukostasis. Microvascular Research 72 86-90. (doi:10.1016/j.mvr.2006.04.002)

Yamagishi SI, Ueda S \& Okuda S 2007a Food-derived advanced glycation end products (AGEs): a novel therapeutic target for various disorders. Current Pharmaceutical Design 13 2832-2836. (doi:10.2174/ 138161207781757051)

Yamagishi SI, Abe R, Jinnouchi Y, Matsui T, Imaizumi T \& Inoue H $2007 b$ Pigment epithelium-derived factor inhibits vascular endothelial growth factor-induced vascular hyperpermeability both in vitro and in vivo. Journal of International Medical Research 35 896-899. (doi:10.1177/ 147323000703500619)

Yamagishi SI, Matsui T, Takenaka K, Nakamura K, Takeuchi M \& Inoue H 2009 Pigment epithelium-derived factor (PEDF) prevents platelet activation and aggregation in diabetic rats by blocking deleterious effects of advanced glycation end products (AGEs). Diabetes/Metabolism Research and Reviews 25 266-271. (doi:10.1002/dmrr.906)

Yang SL, Chen SL, Wu JY, Ho TC \& Tsao YP 2010 Pigment epitheliumderived factor induces interleukin-10 expression in human macrophages by induction of PPAR $\gamma$. Life Sciences 87 26-35. (doi:10.1016/j.lfs.2010.05.007)

Yokoi M, Yamagishi SI, Saito A, Yoshida Y, Matsui T, Saito W, Hirose S, Ohgami K, Kase M \& Ohno S 2007 Positive association of pigment epithelium-derived factor with total antioxidant capacity in the vitreous fluid of patients with proliferative diabetic retinopathy. British Journal of Ophthalmology 91 885-887. (doi:10.1136/bjo.2006.110890)

Yoshida T, Yamagishi SI, Nakamura K, Matsui T, Imaizumi T, Inoue H, Ueno T \& Sata M 2006 Pigment epithelium-derived factor (PEDF) blocks the interleukin- 6 signaling to C-reactive protein expression in Hep3B cells by suppressing Rac-1 activation. Life Sciences 79 1981-1987. (doi:10.1016/j.lfs.2006.06.034)

Yoshida Y, Yamagishi SI, Matsui T, Jinnouchi Y, Fukami K, Imaizumi T \& Yamakawa R 2009 Protective role of pigment epithelium-derived factor (PEDF) in early phase of experimental diabetic retinopathy. Diabetes/ Metabolism Research and Reviews 25 678-686. (doi:10.1002/dmrr.1007) 
Zhang SX, Wang JJ, Dashti A, Wilson K, Zou MH, Szweda L, Ma JX \& Lyons TJ 2008 Pigment epithelium-derived factor mitigates inflammation and oxidative stress in retinal pericytes exposed to oxidized low-density lipoprotein. Journal of Molecular Endocrinology 41 135-143. (doi:10.1677/JME-08-0011)

Zhang Y, Han J, Yang X, Shao C, Xu Z, Cheng R, Cai W, Ma J, Yang Z \& Gao G 2011 Pigment epithelium-derived factor inhibits angiogenesis and growth of gastric carcinoma by down-regulation of VEGF. Oncology Reports 26 681-686.

Zheng Z, Chen H, Zhao H, Liu K, Luo D, Chen Y, Chen Y, Yang X, Gu Q \& Xu X 2010 Inhibition of JAK2/STAT3-mediated VEGF upregulation under high glucose conditions by PEDF through a mitochondrial ROS pathway in vitro. Investigative Ophthalmology \& Visual Science 51 64-71. (doi:10.1167/iovs.09-3511)

Received in final form 5 June 2014

Accepted 11 June 2014

Accepted Preprint published online 13 June 2014
Published by Bioscientifica Ltd. 